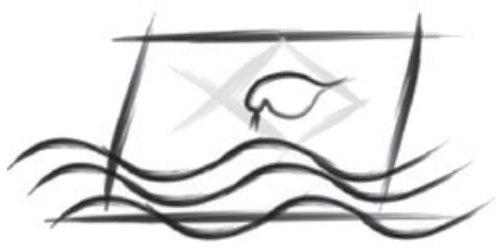

J. Braz. Soc. Ecotoxicol., v. 4, n. 1-3, 2009, 49-54

doi: 10.5132/jbse.2009.01.007

ECOTOX - Brazil

\title{
Comparação entre as Respostas do Clone 4430 e Tradescantia pallida no Teste de Micronúcleos (Trad-MN)
}

\author{
A.C. Mielli, ${ }^{1 *}$ P. H. N. Saldiva ${ }^{1} \&$ G. A. Umbuzeiro ${ }^{2}$ \\ ${ }^{1}$ Laboratório de Poluição Atmosférica Experimental - Faculdade de Medicina - Universidade de São Paulo \\ ${ }^{2}$ Laboratório de Ecotoxicologia Aquática e Limnologia - Faculdade de Tecnologia, \\ Universidade Estadual de Campinas - UNICAMP, Brasil
}

(Received September 22, 2008; Accepted August 11, 2009)

\begin{abstract}
RESUMO
Comparação das respostas do Clone 4430 e Tradescantia pallida no Teste de Micronúcleos (Trad-MN)O teste de genotoxicidade com o clone 4430 do gênero Tradescantia é utilizado mundialmente por vários grupos de pesquisadores. No Brasil, a Tradescantia pallida vem sendo utilizada em substituição ao clone 4430 fornecendo resultados satisfatórios. Entretanto, na literatura, apenas um trabalho comparativo entre as duas espécies foi encontrado, revelando a necessidade de mais estudos para verificação do potencial da Tradescantia pallida em substituição ao clone 4430 no teste Trad-MN. Este estudo teve por objetivo realizar testes comparativos entre as duas plantas, com substâncias utilizadas em estudos anteriores como controles positivos e negativos. Os resultados obtidos nos estudos comparativos demonstraram que a Tradescantia pallida pode substituir o clone 4430 no teste de micronúcleo. Entretanto, grande variação na freqüência de micronúcleos (de 3\% a 8\% para controle negativo e de 5\% a $11 \%$ para controle positivo) foi observada para as substâncias testadas como controles negativos e positivos, indicando baixo poder discriminatório do teste Trad-MN quando Tradescantia pallida é utilizada como organismo indicador.
\end{abstract}

Palavras-chave: Clone 4430, genotoxicidade ambiental, Micronúcleo (MN), Tradescantia pallida.

\section{ABSTRACT \\ Comparison of responses of the Clone 4430 and Tradescantia pallida in the Micronucleus Assay (Trad-MN)}

The Genotoxicity Assay with clone 4430 genus Tradescantia is utilized worldwide in the Tradescantia Micronucleus assay (Trad-MN). In Brazil, several Trad-MN studies have utilized Tradescantia pallida to replace the clone 4430. However, in the literature, only one comparison between the two species was performed, and more studies are necessary to examine the mutagenic potential of Tradescantia pallida for application in the Trad - MN. The present work aims to compare the results of Trad-MN assays between the two plants, in the testing of mutagenic substances (positive controls) and water (as negative controls), to evaluate the utilization potential of Tradescantia pallida for replacing clone 4430. The results obtained showed that Tradescantia pallida can replace clone 4430 in the micronucleus assay, however, the substances testing showed high variation in the micronuclei induction (3\% - 8\% for negative control and $5 \%-11 \%$ for positive control), indicating low discriminating potential of the assay and limited applicability in monitoring programs.

Keywords: Clone 4430, environmental genotoxicity, Micronuclei (MN), Tradescantia pallida. 


\section{INTRODUÇÃO}

O Teste de Micronúcleo com Tradescantia (Trad-MN) é um ensaio de genotoxicidade para detecção de efeitos deletérios provocados por agentes químicos (Gong et al., 2003), poluição atmosférica (Carvalho-Oliveira et al., 2005), drogas (Kim et al., 2003), radiação (Suyama et al., 2002), solo (Majer et al., 2002), água (Crebelli et al., 2005) e pesticidas (Rodrigues et al., $1998 \mathrm{a} ; \mathrm{b}$ ).

O ensaio baseia-se na formação de micronúcleos originados dos fragmentos cromossômicos acêntricos (efeito clastogênico) ou cromossomos inteiros (efeitos aneugênico) que são provocados por agentes mutagênicos (MA et al., 1981, 1991, 1994). Ma e colaboradores (1978) descreveram e padronizaram o teste para o Clone BNL 4430, um híbrido estéril (Tradescantia hirsutiflora $\times$ Tradescantia subcaulis) do gênero Tradescantia. Entretanto, o Clone 4430 tem aplicações limitadas em países tropicais, dada sua sensibilidade ao clima (temperatura e umidade do ar elevadas) e ao ataques de insetos quando as plantas são expostas por períodos prolongados em ambiente aberto, limitando seu uso para estudos de biomonitoramento (Sant'anna, 2003).

No Brasil, alguns estudos têm usado a espécie Tradescantia pallida no monitoramento de poluição atmosférica. Esta espécie é largamente usada como planta ornamental em jardins e canteiros de rodovias e estradas, apresentando resistência natural às intempéries da natureza, além de fácil propagação (Suyama et al., 2002). A Tradescantia pallida foi utilizada com sucesso para detectar mutagenicidade causada pela poluição atmosférica in situ (Carreras et al., 2006), como também em laboratório (Carvalho-Oliveira et al., 2005). Suyama (2002) e colaboradores demonstraram que a Tradescantia pallida e o Clone 4430 apresentam resposta semelhante aos efeitos genotóxicos dos raios-X. Sumita (2003) e colaboradores pesquisaram o acúmulo de alguns metais nas folhas de Tradescantia pallida, obtendo resultados semelhantes àqueles observados com o Clone 4430 (Alves et al., 2001). Tais resultados indicam que a Tradescantia pallida pode ser uma alternativa conveniente em substituição ao Clone 4430 nos testes de micronúcleos.

Visando ampliar os conhecimentos sobre o potencial de utilização da Tradescantia pallida em substituir o clone 4430 na avaliação de mutágenos ambientais, este estudo teve como objetivos:

1) Comparar as respostas obtidas no Teste de Micronúcleo entre a Tradescantia pallida e o Clone 4430 frente a diferentes concentrações de trióxido de arsênio $\left(\mathrm{As}_{2} \mathrm{O}_{3}\right)$, de solução nutritiva de Hoagland e de água de torneira; e

2) Avaliar a resposta da Tradescantia pallida frente a substâncias conhecidamente mutagênicas (controles positivos) e água de diferentes qualidades (controles negativos), substâncias estas que vêm sendo rotineiramente utilizadas e citadas na literatura.

\section{MATERIAL E METODOS}

\section{Teste do Micronúcleo em células germinativas de Tradescantia}

\section{Estudo Comparativo entre Tradescantia pallida e Clone 4430 frente ao Trióxido de Arsênio $\left(\mathrm{As}_{2} \mathrm{O}_{3}\right)$, solução de Hoagland e água de torneira}

Inflorescências jovens (sem flor aberta) das plantas foram coletadas de floreiras cultivadas em jardim de uma área rural, distante de rodovias e indústrias, na Cidade de Caucaia do Alto situada a $50 \mathrm{~km}$ do centro da cidade de São Paulo.

Foram preparadas soluções de $\mathrm{As}_{2} \mathrm{O}_{3}$ (Sigma) nas concentrações 1,0 mM; 2,5 mM e 5,0 mM conforme proposto por Knasmüller (In Bioassays in Plant Cells, 2003) e segundo protocolo estabelecido por Ma e colaboradores (1981) para o clone 4430. As hastes florais (5-10 hastes) foram colocadas em béqueres com solução nutritiva de Hoagland diluída 1:3, por $24 \mathrm{~h}$ para adaptação antes da exposição ao $\mathrm{As}_{2} \mathrm{O}_{3}$. As inflorescências de Tradescantia pallida e do Clone 4430 foram separadas em grupos e expostas por $6 \mathrm{~h}$, tendo como controle negativo a solução nutritiva de Hoagland (diluída 1:3). Após exposição, as inflorescências foram colocadas em uma nova solução nutritiva por um período de recuperação de $24 \mathrm{~h}$, sendo em seguida fixadas em solução de ácido acético e etanol (1:3) e conservadas em álcool $70 \%$ para posterior preparação e análise das lâminas de microscopia.

Paralelamente à realização deste experimento, foram testados dois controles negativos, água de torneira e solução de Hoagland (diluída 1:3). A coleta da água de torneira foi feita no laboratório da Faculdade de Medicina da USP, e a solução de Hoagland foi preparada a partir de macro e micro nutrientes seguindo o protocolo de Hoagland e Arnon (1950). A coleta das plantas, local e tempo de exposição foram os mesmos realizados para o ensaio com o $\mathrm{As}_{2} \mathrm{O}_{3}$.

\section{Estudos das respostas da Tradescantia pallida frente a substâncias mutagênicas e água de diferentes qualidades}

Foram coletadas de 5 - 10 inflorescências de Tradescantia pallida no jardim da Companhia de Tecnologia de Saneamento Ambiental (CETESB), localizada na cidade de São Paulo. Como controles positivos foram utilizados Formaldeído (MERCK) na concentração de 0,1 e $0,2 \%$, Etil metanosulfonato (EMS Sigma) nas concentrações $0,8 \mathrm{mM} \mathrm{e} 8,0 \mathrm{mM} \mathrm{e} \mathrm{As}_{2} \mathrm{O}_{3}$ (Sigma) a $5,0 \mathrm{mM}$. As condições utilizadas como controle negativo foram: água de torneira, água destilada, água ultra pura, água mineral e solução nutritiva de Hoagland (diluída 1:3). Hastes florais foram expostas por 8 horas após período de adaptação de 24 h em solução de Hoagland (diluída 1:3). O período de recuperação foi de $24 \mathrm{~h}$ em solução de Hoagland. A partir desta etapa o procedimento foi realizado de acordo com o descrito no item Preparações das Lâminas

Inflorescências contendo estágio de tétrades jovens foram dissecadas e 5 a 10 lâminas por grupo foram preparadas usando corante carmim. As lâminas foram codificadas de modo que o leitor não conhecesse sua origem, somente identificando-as no 
final das leituras e analisadas quanto à presença de micronúcleos com aumento de $100 \times$ e $400 \times$ em microscópio óptico. Para cada grupo foram avaliadas no mínimo 1500 tétrades e cada lâmina foi considerada uma amostra do grupo (Rodrigues et al., 1999).

\section{Análises Estatísticas}

Os dados obtidos para os diferentes ensaios foram avaliados utilizando-se a análise de variância (ANOVA) seguida pelo post-hoc de Tukey. O programa estatístico utilizado foi o SPSS vs 10 e as amostras foram consideradas significativas quando apresentaram diferenças em relação ao controle negativo com significância mínima de 5\% (p<0,05).

\section{RESULTADOS}

\section{Estudo comparativo entre as respostas da Tradescantia pallida e Clone 4430 frente ao $\mathrm{As}_{2} \mathrm{O}_{3}$, à solução nutritiva de Hoagland e à água de torneira}

Inicialmente foram realizados estudos comparativos com os controles negativos água de torneira e solução nutritiva de
Hoagland, utilizando inflorescências de Tradescantia pallida e do clone 4430 (Tabela 1). Não foi observada diferença significativa entre as médias da freqüência de $\mathrm{MN}$ nesses resultados $(\mathrm{p}=0,842)$, independentemente da planta utilizada $(\mathrm{p}=0,951)$. As médias da freqüência de micronúcleo obtidas para Tradescantia pallida para ambas as condições de teste foram maiores que as obtidas no clone 4430 , porém não significativas $(\mathrm{p}=0,064)$.

As comparações múltiplas pelo método de Tukey revelaram que os resultados obtidos para as doses de $\mathrm{As}_{2} \mathrm{O}_{3}$ testadas foram estatisticamente diferentes do controle negativo $(\mathrm{p}=0,011$ para a dose de 1,0 mM e p $<0,001$ para as doses de 2,5 e 5,0 mM). Os resultados da freqüência de MN na Tradescantia pallida para $\mathrm{o}$ tratamento com o $\mathrm{As}_{2} \mathrm{O}_{3}$ foram significativamente maiores do que aqueles observados no clone 4430 (Tabela 2). Entretanto, não houve diferença significativa das doses nas respostas obtidas para as duas $(\mathrm{p}=0,276)$.

\section{Respostas da freqüência de MN da Tradescantia pallida frente a diferentes substâncias mutagênicas e diferentes fontes de água}

A ANOVA realizada com as médias das freqüências de $\mathrm{MN}$ obtidas para água ultra pura, água de torneira, água mineral,

Tabelas 1 - Freqüências de micronúcleos (MN\%) obtidas em experimento com inflorescências do clone 4430 e de Tradescantia pallida após exposição por $6 \mathrm{~h}$ a solução de Hoagland e água de torneira.

\begin{tabular}{|c|c|c|c|c|}
\hline \multirow[t]{2}{*}{ Solução } & \multicolumn{2}{|c|}{ Clone $4430^{\mathrm{a}}$} & \multicolumn{2}{|c|}{ Tradescantia pallida ${ }^{\mathrm{a}}$} \\
\hline & $\begin{array}{l}\mathrm{N}^{\circ} \text { de tétrades } \\
\text { analisadas }\end{array}$ & $\begin{array}{c}\text { MN/100 tétrades } \pm \text { DP } \\
(\mathrm{MN} \%)\end{array}$ & $\mathrm{N}^{\circ}$ de tétrades analisadas & $\begin{array}{c}\text { MN/100 tétrades } \pm \text { DP } \\
(\mathrm{MN} \%)\end{array}$ \\
\hline Água de torneira & 2100 & $5,0 \pm 1,6^{\mathrm{b}}$ & 4200 & $6,0 \pm 1,9^{c}$ \\
\hline Solução de Hoagland & 3300 & $5,0 \pm 1,2^{\mathrm{b}}$ & 3300 & $6,1 \pm 2,1^{\mathrm{c}}$ \\
\hline
\end{tabular}

Os resultados seguidos pelas mesmas letras não diferem significativamente pelo teste de Tukey $(\mathrm{p}<0,05)$.

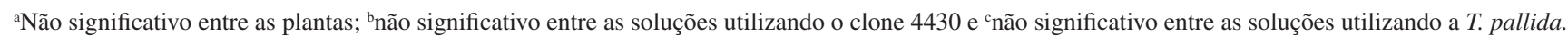

Tabela 2 - Freqüências de micronúcleos (MN\%) obtidas em experimento com inflorescências do clone 4430 e de Tradescantia pallida após exposição por $6 \mathrm{~h}$ a diferentes concentrações de trióxido de arsênio $\left(\mathrm{As}_{2} \mathrm{O}_{3}\right)$.

\begin{tabular}{lcccc}
\hline \multicolumn{1}{c}{ Solução } & Clone 4430 & \multicolumn{2}{c}{ Tradescantia pallida } \\
\hline & $\begin{array}{c}\text { No de tétrades } \\
\text { analisadas }\end{array}$ & $\begin{array}{c}\text { MN/100 tétrades } \pm \\
\text { DP (MN \%) }\end{array}$ & $\begin{array}{c}\text { No de tétrades } \\
\text { analisadas }\end{array}$ & $\begin{array}{c}\text { MN/100 tétrades } \pm \\
\text { DP (MN \%) }\end{array}$ \\
\hline Hoagland (controle negativo) & 1500 & $3,3 \pm 1,09$ & 1500 & $3,6 \pm 0,48$ \\
$\mathrm{As}_{2} \mathrm{O}_{3} 1 \mathrm{mM}$ & 1500 & $4,2 \pm 1,28^{*}$ & 1500 & $6,6 \pm 1,16^{*}$ \\
$\mathrm{As}_{2} \mathrm{O}_{3} 2,5 \mathrm{mM}$ & 1500 & $5,9 \pm 0,94^{*}$ & 1500 & $6,2 \pm 1,62^{*}$ \\
$\mathrm{As}_{2} \mathrm{O}_{3} 5 \mathrm{mM}$ & 1500 & $6,9 \pm 1,07^{*}$ & 1500 & $8,0 \pm 1,92^{*}$ \\
\hline
\end{tabular}

* $\mathrm{p}<0,05$ com relação ao controle negativo (Teste de Tukey)

Tabela 3 - Freqüências de micronúcleos (MN \%) obtidas em experimento com inflorescências de Tradescantia pallida após exposição por $8 \mathrm{~h}$ a água de diferentes qualidades.

\begin{tabular}{lcc}
\hline \multicolumn{1}{c}{ Solução } & Tradescantia pallida \\
\hline & $\begin{array}{c}\text { No de tétrades } \\
\text { analisadas }\end{array}$ & $\begin{array}{c}\text { MN/100 tétrades } \pm \text { DP } \\
(\text { MN \%) }\end{array}$ \\
\hline Solução de Hoagland (grupo controle) & 2100 & $4,76 \pm 1,29$ \\
Ultrapura & 2400 & $5,59 \pm 1,97 \mathrm{n} . \mathrm{s}$ \\
Destilada & 1800 & $8,11 \pm 2,57^{*}$ \\
Mineral & 2400 & $6.33 \pm 2,09 \mathrm{n} . \mathrm{s}$ \\
Torneira & 2700 & $4,67 \pm 0,98 \mathrm{n} \mathrm{s}$ \\
\hline
\end{tabular}

ns: não significativo; *p $<0,05$ com relação ao grupo controle (Teste de Tukey) 
Tabela 4 - Freqüências de micronúcleos (MN \%) obtidas em experimento com inflorescências de Tradescantia pallida após exposição por $8 \mathrm{~h}$ a diferentes substâncias mutagênicas.

\begin{tabular}{lcc}
\hline \multicolumn{1}{c}{ Substância } & Tradescantia pallida \\
\hline & $\begin{array}{c}\text { No de tétrades }_{\text {analisadas }} \\
\text { Água ultrapura (controle negativo) }\end{array}$ & $\begin{array}{c}\text { MN/100 tétrades } \pm \text { DP } \\
(\mathrm{MN} \%)\end{array}$ \\
Formaldeído 0,1\% & 1500 & $2,74 \pm 1,48$ \\
Formaldeído 0,2\% & 1500 & $6,94 \pm 2,65 \mathrm{~ns}$ \\
E M S 0,8 mM & 2400 & $10,34 \pm 5,40^{*}$ \\
E M S 8,0 mM & 2400 & $5,96 \pm 2,03 \mathrm{~ns}$ \\
$\mathrm{As}_{2} \mathrm{O}_{3} 5,0 \mathrm{mM}$ & 1200 & $11,25 \pm 5,85^{* *}$ \\
\hline
\end{tabular}

ns: não significativo; $* \mathrm{p}<0,01 ; * * \mathrm{p}<0,05$

E M S - etil metanossulfonato

água destilada e solução nutritiva de Hoagland, indicou que essas soluções apresentaram respostas diferentes entre si $(p=0,003)$. Utilizando a solução de Hoagland como grupo controle (teste de Tukey) foi observado que apenas a água destilada apresentou resultado significativo (Tabela 3 ).

Os dados de freqüências de MN obtidos para as diferentes substâncias mutagênicas testadas apresentaram diferenças significativas $(\mathrm{p}=0,008)$. Foi observado que o formaldeído $0,2 \%$ e o EMS $8,0 \mathrm{mM}$ induziram aumento significativo na freqüência de micronúcleos quando comparados ao controle negativo, as demais substâncias e doses testadas não apresentaram respostas significativas (Tabela 4).

\section{DISCUSSÃO}

Os primeiros ensaios realizados visaram comparar as respostas da freqüência média de micronúcleos entre Tradescantia pallida e o clone 4430 após exposição ao $\mathrm{As}_{2} \mathrm{O}_{3}$, à solução de Hoagland e à água de torneira, que são freqüentemente utilizados como controle positivo e negativo, respectivamente, em bioensaios com vegetais (Knasmüller et al., 1998; CarvalhoOliveira et al., 2005).

As repostas obtidas para a solução de Hoagland e água de torneira não foram significativamente diferentes para as duas plantas (Tabela 1). Sabe-se que a água de torneira apresenta mutagenicidade devido à presença de substâncias cloradas (Sanchez et al., 1988), porém, as respostas obtidas neste estudo permitem inferir que o teste não é sensível para detectar a mutagenicidade desses compostos nas concentrações presentes na água de torneira testada.

Visando à possibilidade de substituição do clone 4430 pela Tradescantia pallida, os dados apresentados na Tabela 2 mostram que as médias de micronúcleos para a Tradescantia pallida foram maiores nas mesmas condições de teste que as do clone 4430, entretanto, as duas plantas comportaram-se de forma semelhante em relação às doses-respostas obtidas. Estes resultados, somados àqueles obtidos anteriormente por Suyama (2002) para raios X, sugerem que a Tradescantia pallida pode substituir o clone nos testes Trad-MN.
Após os testes comparativos entre as duas plantas, foram realizados dois novos experimentos utilizando apenas inflorescências de Tradescantia pallida expostas a diferentes substâncias mutagênicas (controles positivos) e água de diferentes qualidades (controles negativos) que foram anteriormente utilizadas por outros autores. As respostas obtidas neste estudo indicaram que a água destilada foi significativamente diferente do grupo (Tabela 3), indicando que a mesma não seria um controle negativo adequado. $\mathrm{O}$ resultado obtido para a água destilada enquadrou-se, neste caso, na mesma faixa de freqüência dos resultados obtidos para as substâncias mutagênicas (Tabela 4). Quando o teste com substâncias mutagênicas foi realizado, utilizou-se a água ultrapura como controle negativo, sendo que o valor obtido para este controle foi diferente do obtido no teste com fontes diferentes de água (Tabela 3 ), esta obteve um valor mais baixo, indicando alta variação nas respostas basais desse ensaio. Os autores não conseguiram associar fatores ambientais que pudessem explicar essa variação.

Dentre as substâncias e concentrações testadas como controles positivos, pode-se afirmar que o formaldeído a $0,2 \%$ e o $\mathrm{As}_{2} \mathrm{O}_{3}$ a $5,0 \mathrm{mM}$ foram significantes quando comparados ao controle negativo (Tabela 4). Estudos realizados por Sandhu e colaboradores (citado por Rodrigues et al., 1998b) e Steinkellner (1998) e seus colaboradores já haviam empregado o $\mathrm{As}_{2} \mathrm{O}_{3}$ como controle positivo utilizando o clone 4430, no entanto, os autores não apresentam os valores numéricos obtidos para compará-los com os deste estudo.

A Figura 1 compara dados da freqüência de MN para diferentes controles positivos e negativos obtidos por diferentes autores, tanto para o clone 4430 como para a Tradescantia pallida, com aqueles obtidos neste estudo. Observa-se grande variação na amplitude de respostas tanto para os controles negativos $(<1 \%-8 \%)$ como positivos $(5 \%-11 \%)$. Esses dados confirmam os achados de White e Claxton (2004) que indicaram o baixo poder discriminatório do teste de MN com Tradescantia.

Testes de mutagenicidade com plantas podem ser úteis em uma das etapas da avaliação de risco genotóxico para os seres humanos: a etapa de avaliação do perigo. Resultados positivos podem indicar a necessidade de mais testes com espécies de maior relevância para o ser humano. 


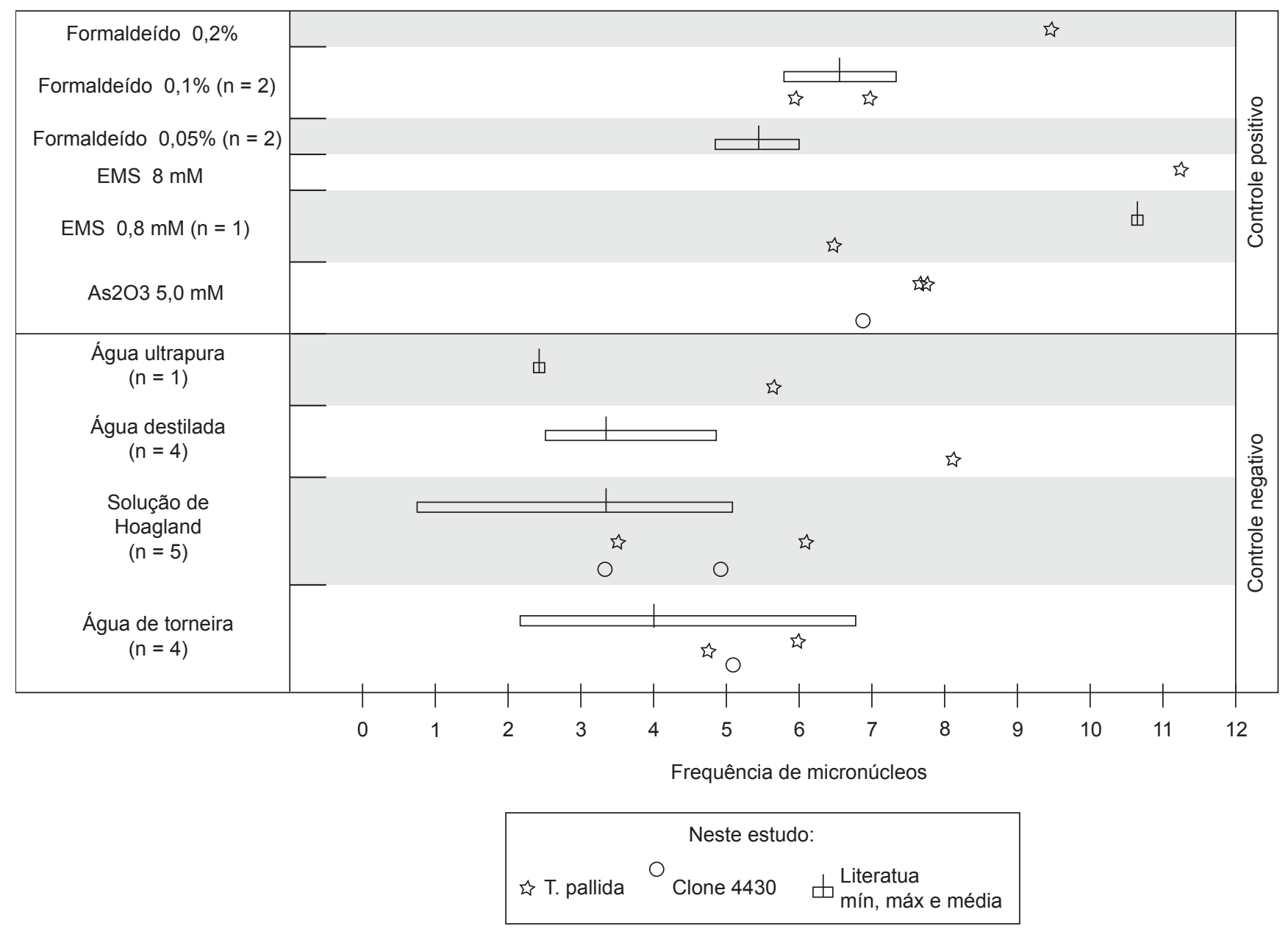

Figura 1 - Comparação da freqüência de micronúcleos (MN \%) obtidas neste estudo com a literatura (Fonte: Batalha et al, 1999; Carvalho-Oliveira et al., 2005; Cotelle et al., 1999; Klumpp et al., 2004; Ma et al., 1994; Monarca et al., 2002; Rodrigues et al., 1998a; Santos et al., 2004; Steinkellner et al., 1998).

Devido à restrição cada vez maior do uso de animais de laboratório, os testes com bactérias, plantas e culturas celulares vêm ganhando importância, porém sua interpretação deve ser muito cautelosa e realizada conjuntamente com outros dados. Considera-se que quanto mais próximo do ser humano estiver o organismo teste, mais relevante se tornam os resultados obtidos para se inferir riscos a saúde humana.

Os dados obtidos neste trabalho sugerem que o teste de MN em células germinativas de Tradescantia deve ser usado com cautela em estudos de biomonitoramento ambiental, devido ao seu baixo poder discriminatório. Talvez maior controle das condições ambientais, como estufas com ar filtrado ou outros recursos, possam ser utilizados para controlar as variações das repostas, porém esses esforços levariam a maior custo analítico especialmente quando associado ao laborioso procedimento de contagem dos micronúcleos.

\section{REFERÊNCIAS BIBLIOGRÁFICAS}

ALVES, E.S., GIUSTI, P. M., DOMINGOS, M., SALDIVA, P. H. N., GUIMARÃENS, E. T. \& LOBO, D. J., 2001, Estudo anatômico foliar do Clone híbrido 4430 de Tradescantia: alterações decorrentes da poluição aérea urbana. Rev. Brasil. Bot., V4 (suplemento): 567-576.
BATALHA, E.T., GUIMARÃES, E.T., LOBO D.J., LICHTENFELS, J.F.C., DEUR T., CARVALHO, H. A., ALVES, E., DOMINGOS, M., RODRIGUES, G. S. \& SALDIVA, P.H.N., 1999, Exploring the clastogenic effects of air pollutants in São Paulo (Brazil) using the Tradescantia micronuclei assay. Mutation Research, v. 426, n.2, 229-232.

BIOASSAYS IN PLANT CELLS - for improvement of ecosystem and human health. A course manual, 2003, Edited by Jolanta Maluszynska and Michael Plewa. Vienna, Austria.

CARRERAS, H.A., PIGNATA, M.L. \& SALDIVA P.H.N., 2006, In situ monitoring of urban air Córdoba, Argentina using the Tradescantia-micronucleus (Trad-MCN) bioassay. Atmospheric Environ., vol. 40: 7824-7830.

CARVALHO-OLIVEIRA, R., POZO, R.M.K., LOBO, D.J.A., LICHTENFELS, A.J.F. \& SALDIVA, P.H.N., 2005, Diesel emissions significantly influence composition and mutagenicity of ambient particles: a case study in São Paulo, Brazil. Environ. Research, vol. 98: 1-7.

COTELLE, S. \& MASFARAUD, J.F., 1999, Assessment of the genotoxicity of contaminated soil with the Allium/Viciamicronucleus and the Tradescantia-micronucleus assays. Mutation research, 426: 167-171.

CREBELLI, R., CONTI, L., MONARCA, S., FERETTI, D., ZERBINI, I., ZANI, C., VESCHETTI, E., CUTILLI, D. \& OTTAVIANI, M., 2005, Toxicity of the disinfection by products 
resulting from peracetic acid or hypochlorite disinfected sewage wastewater. Water Res., 39:1105-1113.

GONG, P., KUPERMAN, R. G. \& SUNAHARA, G. I., 2003, Genotoxicity of 2, 4- and 2, 6-dinitrotolueno as measured by the Tradescantia micronucleus (Trad-MCN) bioassay. Mutation Research, 538: 13-18.

KLUMPP, A., ANSEL, W., FOMIN, A., SCHNIRRING, S. \& PICKL, C., 2004, Influence of climatic conditions on the mutations in pollen mother cells of Tradescantia clone 4430 and implications for the Trad-MCN bioassay protocol. Hereditas, 141: 142-148.

KNASMUlleR, S. \& GOTTMANN, E., 1998, Detection of genotoxic effects of heavy metal contaminated soils with plant bioassays. Mutation Research/Genetic Toxicology and Environmental Mutagenesis 420 (1-3): 37-48.

KIM, J. K. \& SHIN, H. S., 2003, Genotoxic effects of volatile organic compounds in a chemical factory as evaluated micronucleus assay and by chemical analysis. Mutation Research, 541 (1-2): 55-61.

HOAGLAND, D. R. \& ARNON, D.I., 1950, The water-culture method for growing plants without soil. Univ. Calif. Agric. Exp. Stn., Berkeley, CA, Circular No. 347: 1-39.

MAJER, J. B. J., TSCHERKO, D., PASCHKE, A., WENNRICH, R., KUNDI, M., KANDELER, E. \& KNASMULLER, S., 2002, Effects of heavy metal contamination of soils on micronucleus induction in Tradescantia and microbial enzyme activities: a comparative investigation. Mutation Res., 515: 111-124.

MA, T.H., CABRERA, G.L., CHEN, R., GILL, B.S., SANDHU, S. S. \& SALAMONE, M. F., 1994, Tradescantia Micronucleus Bioassay. Mutation Research, 310: 221- 230.

MA, T.H., 1991, Tradescantia micronucleus bioassay and pollen tube aberration test for in situ monitoring and mutagen screening. Environmental Health Perspective, 37:85-90.

MA, T.H., 1981, Tradescantia Micronucleus Bioassay and Pollen Tube chromatid Aberration Test for un Situ Monitoring and Mutagen Screening. Environmental Health, 37:85-9.
MA, T.H., SPARROW, A. H. \& NAUMAN, A. F., 1978, Effect of 1,2-dibromoethane (DBE) on meiotic chromosomes of Tradescantia. Mutation Research, 58: 251-258.

RODRIGUES, G.S., PIMENTEL, D. \& WEINSTEIN L.H., 1998a, In situ assessment of pesticide mutagenicity in an integrated pest management program I - Tradescantia micronucleus assay. Mutation Research, 412: 235-244.

RODRIGUES, G.S., MA T.H., PIMENTEL, D. \& WEINTEIN, L.N., 1998b, Tradescantia bioassays as monitoring systems for environmental mutagenesis: a review. Critical Reviews in Plant Sciences, 16: 325-359.

RODRIGUES, G.S., 1999, Bioensaios de Toxicidade Genética com Tradescantia. Jaguariúna (SP): Embrapa Meio Ambiente. Documentos 14. 56 p.

SANCHEZ, P. S., SATO, M. I.Z., PASCHOAL, C.M.R.B., ALVES, M., N., FULAN, E.V.\& MARTIM, M T., 1988, Toxicity assessment of industrial effluents from São Paulo State, Brazil, using short term microbial assays. Toxicity Assessment, 3: 55-80.

SANTOS, I. T. Q. P., 2004, Avaliação da atividade clastogênica do resíduo catalítico industrial, por meio do bioensaio de micronúcleos com Tradescantia pallida c.v. purpurea (tese). São Paulo. Faculdade de Medicina, Universidade de São Paulo.

STEINKELLNER, H; MUN-SIK, K., HELMA, C., ECKER, C.S., MA, T.H.; KUNDI, M. \& KNASMULLER, S.,1998, Genotoxic effects of Heavy Metals: comparative investigation with plant bioassays. Environ. Mol. Mutag., 31:183-191.

SUMITA, N.M., 2003, Tradescantia pallida cv. Purpurea Boom n the Characterization of Air Pollution by Accumulation of Trace Elements (tese). Faculdade de Medicina, Universidade de São Paulo, São Paulo.

SUYAMA, F., GUIMARÃES, E.T., LOBO, D.J.A. \& SALDIVA, P.H.N., 2002, Pollen mother cells of Tradescantia clone 4430 and Tradescantia pallida var. purpurea are qually sensitive to the clastogenic effects of x-rays. Brazilian Journal of Medical and Biological Research, 35:127-129. 